\title{
Spatial and temporal variation in the association between temperature and salmonellosis in NZ
}

\author{
Aparna Lal, ${ }^{1}$ Simon Hales, ${ }^{2}$ Martyn Kirk, ${ }^{1}$ Michael G. Baker, ${ }^{2}$ Nigel P. French ${ }^{3}$
}

\begin{abstract}
nthropogenic changes in climate have been implicated in the resurgence and spread of infectious diseases in humans. ${ }^{1}$ Climate change will compound the effects of globalisation, population growth and social and demographic inequalities key determinants of infectious disease risk. ${ }^{2}$ Uncertainties around the influence of weather and climate on infection risk has been recognised as a key challenge in quantifying the impact of climate change on health. ${ }^{3}$

Globally, non-typhoidal salmonellosis is a leading cause of enteric infections. ${ }^{4}$ In New Zealand, rates of non-typhoidal salmonellosis are among the highest reported for any developed country. ${ }^{5}$ Previous studies have documented a positive association between salmonellosis and temperature. ${ }^{6,7}$ These findings suggest that future climate change will influence incidence patterns in NZ. While the positive association between non-typhoidal salmonellosis and increasing temperature has been reported from Europe, Canada, the United States, Australia and $\mathrm{NZ}{ }^{7-12}$ there is limited information on the short-term (weekly) and temporally lagged association of temperature with salmonellosis risk across regions. As Salmonella spp. are sensitive to temperature changes, associations between temperature and disease are likely to be on a shorter time scale than monthly time scales. Higher temperatures may result in, for example, rapid growth of Salmonella spp. in food storage and preparation situations where there is inadequate refrigeration. ${ }^{13}$ Understanding spatial variations in the short term and delayed effects of temperature can provide
\end{abstract}

\begin{abstract}
Objective: Modelling the relationship between weather, climate and infectious diseases can help identify high-risk periods and provide understanding of the determinants of longer-term trends. We provide a detailed examination of the non-linear and delayed association between temperature and salmonellosis in three New Zealand cities (Auckland, Wellington and Christchurch).

Methods: Salmonella notifications were geocoded to the city of residence for the reported case. City-specific associations between weekly maximum temperature and the onset date for reported salmonella infections (1997-2007) were modelled using non-linear distributed lag models, while controlling for season and long-term trends.

Results: Relatively high temperatures were positively associated with infection risk in Auckland $(n=3,073)$ and Christchurch $(n=880)$, although the former showed evidence of a more immediate relationship with exposure to high temperatures. There was no significant association between temperature and salmonellosis risk in Wellington.

Conclusions: Projected increases in temperature with climate change may have localised health impacts, suggesting that preventative measures will need to be region-specific. This evidence contributes to the increasing concern over the public health impacts of climate change.
\end{abstract}

Key words: temperature, salomonellosis, non-linear, lagged

insight into locality-specific factors that may be sensitive to temperature and important for transmission. Analysing how the association of non-typhoidal salmonellosis incidence may vary non-linearly at a given temperature and a given lag will allow us to identify periods of greatest public health risk in the short term. The impacts on population health of projected changes in temperature due to climate change will depend on regionspecific population attributes. A comparison of the association between salmonellosis risk and temperature across regions and over the short term can provide insight into the potential mechanisms that underlie these patterns and identify those amenable to intervention. Such a study can also provide information on when the interventions can achieve the greatest reduction in disease. The ultimate aim is to minimise disease burden due to future climate change.

The main aim of the present multi-city study is to describe the association between weekly maximum temperature and nontyphoidal salmonellosis risk in the cities of Auckland, Wellington and Christchurch using distributed lag non-linear models (DLNMs). These models specifically and simultaneously account for the non-linear exposureresponse relationship as well as temporally lagged associations without making any $a$ priori assumptions about the shape of the exposure-response curve..$^{14,15}$ This method also allows the identification of existence of thresholds beyond which weather-disease relationships might vary. 16,17

\footnotetext{
1. National Centre for Epidemiology and Population Health, Australian National University, Australian Capital Territory 2. Department of Public Health, University of Otago, New Zealand.

3. Hopkirk Research Institute, Massey University, New Zealand

Correspondence to: Dr Aparna Lal, National Centre for Epidemiology and Population Health, The Australian National University, Canberra, ACT 0200;

e-mail: aparnal49@gmail.com

Submitted: October 2014; Revision requested: December 2014; Accepted: March 2015

The authors have stated they have no conflict of interest.
} 


\section{Methods}

\section{Disease notification data}

All cases of salmonellosis notified in NZ during the period 1997-2007 were obtained from the National Notifiable Disease Surveillance system. ${ }^{18}$ For notifications, cases were defined as a clinical illness with appropriate laboratory confirmation. ${ }^{19}$ Laboratory confirmation requires isolation of salmonella species from a clinical specimen. ${ }^{19(222)}$ In total, 4,857 cases of (nontyphoidal) salmonellosis were included in the analysis. Using the onset of illness date, cases were aggregated into counts by week over the study period. For each reported infection, we had information on the 2006 National Census of Population Census Area Unit (CAU) of residence. A CAU is a non-administrative, geographical unit defined by Statistics NZ, each of which comprises a population of 3,000-5,000 people. The CAUs that covered Auckland, Christchurch and Wellington were selected for further analyses. These areas together represent the three most populous regions in NZ, accounting for nearly $60 \%$ of the total population estimated in 2006.

\section{Temperature data}

Meteorological data for Auckland, Wellington and Christchurch were obtained from the NIWA National Climate Centre database (http://cliflo.niwa.co.nz). The average maximum daily temperature $\left({ }^{\circ} \mathrm{C}\right)$ from January 1997 to December 2007 for all stations within each city (Auckland, Wellington, Christchurch), with complete data for the time period 1997-2007, was downloaded. Daily values were aggregated to weekly values and averaged across the stations in the region. Figure 1 shows the weekly average maximum temperature range across all three cities.

\section{Data analysis}

The weekly counts of cases and weekly maximum temperature were linked by date. Spearman's correlation was used to determine the correlation between the weekly number of notifications and the weekly average maximum temperature in each city. A distributed lag non-linear model (DLNM) with Poisson error term was used to simultaneously describe non-linear and delayed dependencies in the association between average weekly maximum temperature and disease..$^{20,21}$ Briefly, the DLNM allows the effect of an exposure event (in this case, temperature) to be distributed over a specific period of time, simultaneously estimating the different nonlinear associations with temperature at each lag period and also estimating the non-linear relationships across lags, thus providing a comprehensive picture of the exposureresponse relationship. ${ }^{20}$

A DLNM with a maximum lag of six weeks was used to estimate the cumulative association with temperature over the current week and the previous six weeks. Previous studies of weather-related variations and salmonellosis have reported a lag that persists for up to five to six weeks. ${ }^{10,11}$ For each city, the temperature-salmonella relationship was modelled using a quadratic B-spline with two equally spaced knots, while the temporal structure was modelled using a natural cubic B-spline with two equally spaced knots over lags $0-6 .^{22}$ With regards to temperature, where a null exposure cannot be defined, we used the mean temperature as a reference point to allow comparisons of the exposure-response association across cities. The non-linear association was modelled using a polynomial B-spline using 3

\section{Figure 1: The range of average maximum weekly} temperatures across the three cities from 1997-2007.

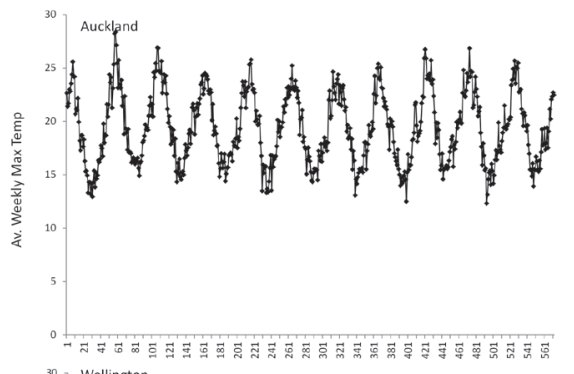
30 . Wellingto
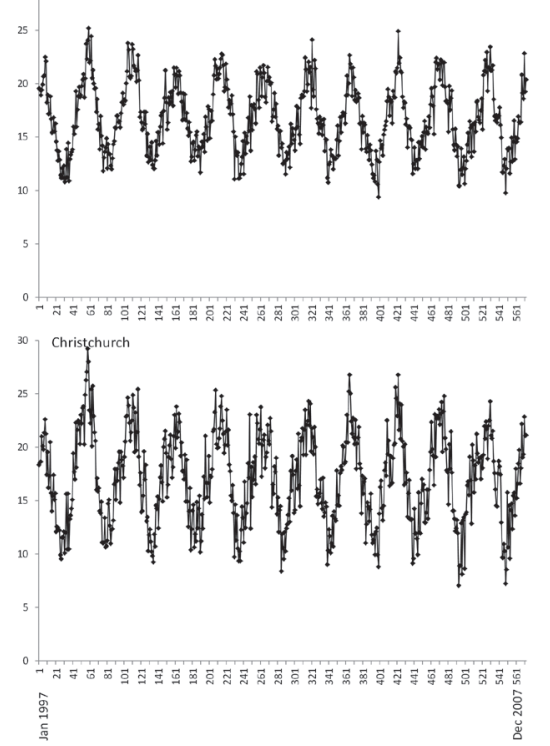

$\mathrm{df}$ for temperature and $2 \mathrm{df}$ for the lag space for temperature. We incorporated natural cubic spline for time, with $6 \mathrm{df}$ to control for seasonal effect and long term trend over the time period. ${ }^{23,24}$ Model fit was evaluated using AIC values. All analyses were performed using R software (version 2.15.1). ${ }^{25}$ The "dlnm" package was used to create the models. ${ }^{15}$ Model residuals were checked to evaluate adequacy of model fit.

In each of the three cities, the following model was used:

$Y_{w} \sim \operatorname{Poisson}\left(\mu_{w}\right)$

$$
\log \left(\mu_{t}\right)=\alpha+\beta T_{t, l}+S(\text { time }, 6 \times \text { year })
$$

where $w$ is the week in which the case was reported; $Y_{w}$ is the number of salmonella infections in week $w$; $a$ is the intercept; $T_{t, 1}$ is the matrix obtained by the DLNM using $3 \mathrm{df}$ for temperature and $2 \mathrm{df}$ for the lag space for temperature; $\beta$ is the vector of coefficients for $T_{t, 1}$ and $/$ is the lag week. $S($.) is the natural cubic spline.

To describe the relationship between temperature and salmonellosis in each city over the six weeks, we plotted the relative risks against temperature and lags. Lagspecific associations between temperature and salmonellosis risk were assessed at lag 2 and lag 4 weeks. Relative risk (RR) is the change in salmonellosis risk for a unit change in exposure, i.e. for temperature, a $1^{\circ} \mathrm{C}$ increase from the average weekly maximum temperature.

\section{Results \\ Descriptive statistics}

The average weekly temperature was $19.3^{\circ} \mathrm{C}$ for Auckland, $16.8^{\circ} \mathrm{C}$ for Wellington and $17.1^{\circ} \mathrm{C}$ for Christchurch. The total number of notified cases, with onset date reported, was 3,073 in Auckland, 880 in Wellington and 904 in Christchurch. The average weekly number was five cases in Auckland, and two in both Wellington and Christchurch. Based on the estimated resident population from the 2006 National Census, the average annual incidence of reported salmonellosis was 21.43 illnesses/100,000 population in Auckland city; 44.57 illnesses/100,000 population in Wellington; and 23.58 illnesses/100,000 population in Christchurch. Spearman's rank correlation coefficients between weekly average maximum temperature and cases were 0.31 (Standard Error S.E. 0.03) in Auckland, 0.18 (S.E. 0.04) in Wellington and 0.22 (S.E.0.04) in Christchurch. 


\section{Association of temperature with salmonellosis risk}

The overall association between temperature and relative risk of salmonellosis is shown in the three-dimensional plot of the relative risk (RR) along temperature change and lags of up to six weeks (Figure 2). These surface plots are a deterministic representation of the complex non-linear relationships and do not provide estimates of uncertainty. The association with temperature appeared to be non-linear and temporally lagged for all three cities. In Auckland, an increase in the relative risk of salmonellosis was associated with high temperatures, over the $90^{\text {th }}$ percentile of the weekly maximum temperature range $\left(24^{\circ} \mathrm{C}\right)$ at a lag of two weeks. In contrast, in Wellington, there appeared to be an increase in relative risk at a lag of 5-6 weeks following exposure to cool temperatures $\left(25^{\text {th }}\right.$ percentile of weekly maximum temperature $14^{\circ} \mathrm{C}$ ). In Christchurch, an increase in salmonellosis relative risk following both cool and hot temperatures between lags two to four weeks was evident, although the increase in salmonellosis associated with higher temperatures was much greater.

Figure 3 shows the association of temperature and salmonellosis relative risk after two weeks and after four weeks with $95 \%$ confidence intervals across the three cities. In Auckland, a high temperature was associated with a significant increase in salmonellosis after an apparent threshold (risk at average temperature) value of $20^{\circ} \mathrm{C}$. After four weeks, this association became negative after $20^{\circ} \mathrm{C}$, although it was not significant. In Wellington, although the estimated non-linear trend suggests a peak in risk associated with a temperature of $22.5^{\circ} \mathrm{C}$ at a lag of two weeks, the $95 \%$ credible intervals were wide and crossed the null value. After four weeks, the association was negligible. In Christchurch, after a lag of four weeks, temperatures above $27^{\circ} \mathrm{C}$ showed a significant positive association with salmonellosis risk. Diagnostic analysis of model residuals showed that they followed a normal distribution (Supplementary Figure S1, available online).

\section{Discussion}

There is growing evidence to suggest that projected climate change will affect health. To our knowledge, this is the first study to explore the non-linear and time-dependent association of temperature and salmonellosis risk across cities. Study findings indicate that
Figure 2: City-specific three dimensional plot showing the Relative Risks (RR) for salmonellosis along a gradient of temperature and weeks, adjusted for seasonal and inter-annual variation.
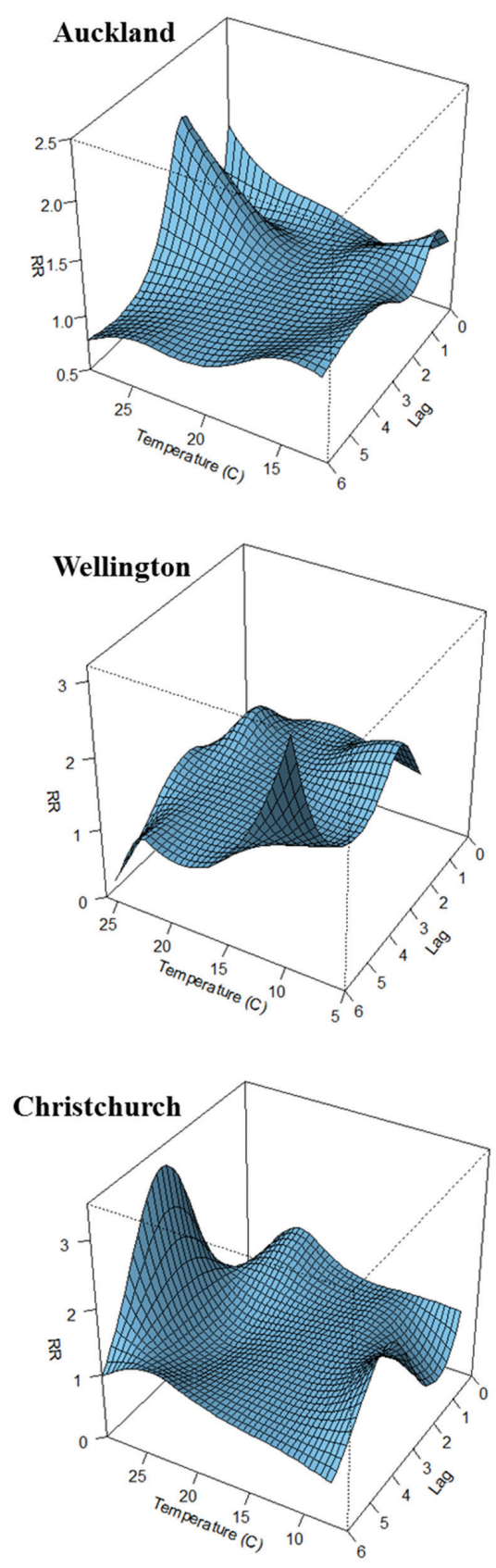

increases in weekly maximum temperatures above average are associated with an increased risk of salmonellosis in Auckland and Christchurch.

The positive association between temperature and salmonellosis risk in Auckland and Christchurch is consistent with previous studies from $\mathrm{NZ}^{6}$ and elsewhere. ${ }^{26-28}$ Salmonellosis tends to peak in summer and decrease in winter. ${ }^{10,29}$ Increased temperatures could provide optimal conditions to enhance pathogen survival and multiplication and therefore increase pathogen load in food ${ }^{9,10}$ and environmental reservoirs ${ }^{30}$ and prolong transmission seasons. ${ }^{31}$ Foreign travel may also partly explain summer peaks in salmonellosis ${ }^{32}$ and warmer temperatures may influence human behaviour, such as more frequent barbecues, providing opportunities for transmission of bacteria through consumption of under-cooked food. ${ }^{33}$ We found evidence of a stronger association of temperature with salmonellosis risk in Auckland as compared to Christchurch. Similar regional variations were observed in Australia, where Zhang et al. (2010) found that lag times for the impact of temperature on salmonella infections were shorter in tropical Townsville compared to subtropical Brisbane. The authors suggested that this minor difference may be due to the narrower range of temperatures in tropical Townsville. ${ }^{8}$

The apparent association of elevated temperature with salmonellosis risk is lagged by several weeks in Auckland and Christchurch. This suggests that the effects of temperature may not be mediated by direct effects on salmonellosis multiplication in food close to the point of consumption. The incubation time for Salmonella spp. is $12-48$ hours, so we would expect that factors operating close to the point of infection would have a minimal lag time. These potential long-lagged effects raise important questions about the biological pathways through which temperature may influence salmonellosis risk. This temporally lagged association of disease risk with high temperatures may reflect an environmental source of infection that is influenced by temperature, such as direct exposure to faeces from infected animals, resulting from a longer chain of temperature-dependent events in reservoir hosts prior to the point of human exposure. ${ }^{34-36}$ For example, epidemics of salmonellosis in wild bird populations, which could be enhanced by temperaturedependent transmission, have also been identified as a source of human disease in the South Island of NZ. ${ }^{37,38}$ Similarly, it is plausible that these more 'distal' temperature effects could operate in food growing areas (for example through contamination of grain, fruit, vegetables and others foods) that are removed in time and place from where these contaminated foods are subsequently consumed. Findings from these studies suggest the need for more sophisticated investigation to identify and control these more distant sources of salmonellosis. 
Lal et al.

Unlike Auckland and Christchurch, there were no significant associations between temperature and salmonellosis incidence in Wellington. This could be due to chance (e.g. insufficient data resulting in low power) as the lowest number of cases were reported from Wellington. The shape of the relationship between disease incidence and temperature at a lag of two weeks indicates an upward trend with a peak at $22.5^{\circ} \mathrm{C}$; however, this was associated with wide confidence intervals and was non-significant. Alternatively, the absence of a significant relationship could be due to differences in reporting between regions. Finally, it could also suggest that there really is no biologically meaningful association between temperature, lag and cases in Wellington due to differences in the aetiology/epidemiology of the disease in this part of NZ.

The non-linear and temporally delayed association between temperature and salmonellosis risk may vary by region in NZ. An increase in the frequency and intensity of extreme temperatures is expected under current climate change scenarios for NZ. ${ }^{34-}$

${ }^{36}$ The period 1997-2007 covers the big epidemic of Salmonella DT160 that started in Christchurch in 1999 in sparrows and spread very rapidly all over NZ. ${ }^{37}$ In contrast,
Figure 3: Estimated association of average maximum weekly temperature with salmonellosis notifications across the three cities after a lag of two (Lag 2) and four weeks (Lag 4), adjusted for mean temperature, seasonal and inter-annual variation. The red lines are the relative risks and the grey lines are $95 \%$ confidence intervals.

Auckland

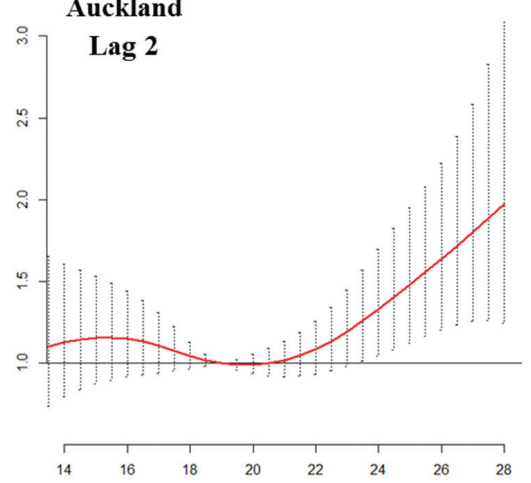

Wellington

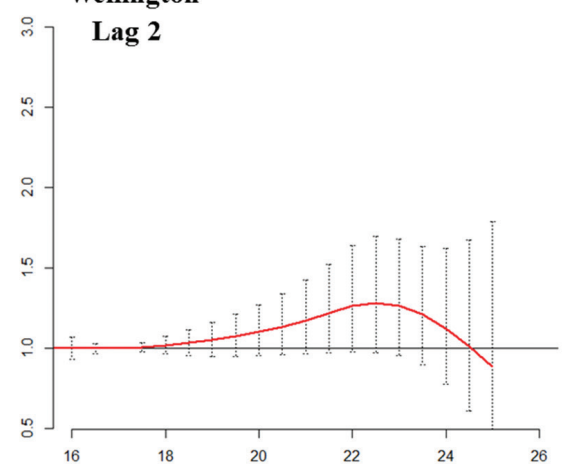

Christchurch

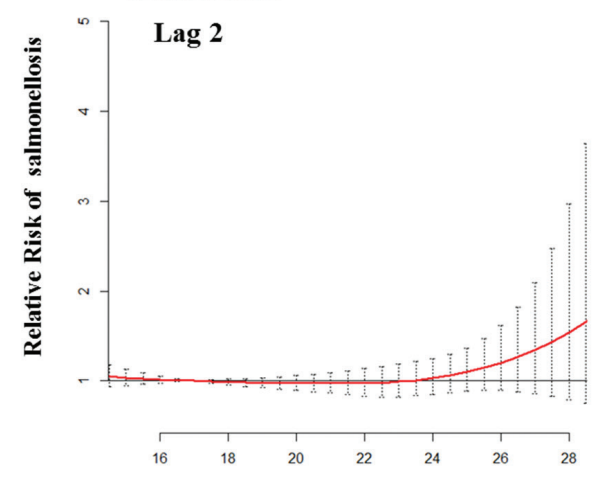

Temperature
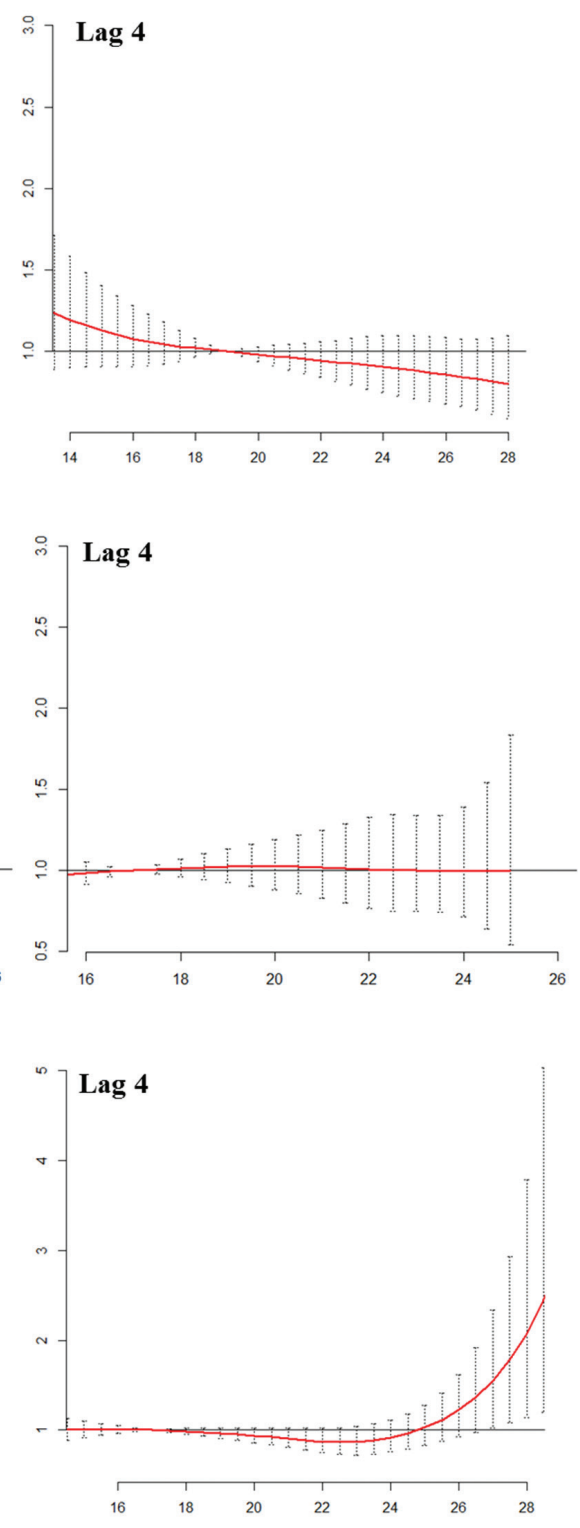

S. Brandenburg stayed largely in South Island and was associated with sheep. ${ }^{38}$ So there are differences in the distribution of potential hosts, particularly livestock hosts, that could explain regional differences. In addition, Māori and Pacific Peoples and populations residing in socioeconomically deprived areas are more severely affected by salmonellosis. ${ }^{5}$ Thus, in areas that provide optimal temperature conditions to favour the replication of Salmonella spp., the health risks for Indigenous and socioeconomically disadvantaged populations are likely to be amplified by climate change.

While climatic extremes are strongly associated with both sporadic enteric infections and outbreaks, ${ }^{39,40}$ neglecting the considerable variation in the magnitude and timing of such events may misrepresent the overall effect. ${ }^{41}$ Results from this study illustrate that traditional time series methods of describing associations between environmental exposures and disease incidence may not adequately capture the non-linear and delayed effects. Disease response to interacting environmental and demographic variables is seldom linear. While results from this study are preliminary and simplistic, in that non-climatic factors were not accounted for, they highlight the complexity of the potential mechanisms through which future climate change may influence disease risk. Studies on the independent influence of local climatic variation on sources of infection, reservoirs, and patients are needed in the future.

This analysis was limited by data quality, as notified cases represent only a portion of actual incidence in the community ${ }^{42}$ and may be not be representative of disease characteristics. However, no major changes were made to the surveillance of these notifiable diseases from 1997-2007 (except for the addition of direct laboratory notification in 2008). The similar temporal trend in salmonellosis notifications and hospitalisations suggests that notifications do provide a fairly stable and consistent measure of disease incidence. ${ }^{5,43}$ Consequently, the completeness of case ascertainment is likely to have remained the same over this time period. It seems unlikely that there were substantial seasonal variations in reporting that might have introduced bias. Although the patterns reported here could differ by pathogen strain, ${ }^{44}$ which may have different sensitivities to climatic factors ${ }^{45}$ and varying incubation times, ${ }^{46}$ strain-specific information 
was not available for this study. Also, the bacterial dose that patients were exposed to may have influenced the patterns reported. In addition, although our analysis focused on sporadic cases, we acknowledge that undetected outbreak-associated cases may have been included in this analysis and could have influenced the patterns found here. Finally, socioeconomic characteristics were not available in the disease data. However, while disease incidence is mediated by a variety of interacting factors, socioeconomic factors are relatively stable over time so cannot confound the short-term temporal associations reported here. Although these results are preliminary, we were able to detect an association between temperature and salmonellosis risk, with an apparent threshold temperature.

In conclusion, for a climate-sensitive disease like salmonellosis, strategies for the prevention and control of infection should take into account variability in local weather conditions. Results from this study highlight regional variations in the association between temperature and salmonellosis. These variations may reflect different transmission pathways. The pathways through which temperature may affect salmonellosis may be direct or indirect, as discussed above. To advance our understanding of the potential health impacts of climate change we need to recognise that the magnitude and nature of climate-disease relationships will vary geographically and over the short term.

\section{References}

1. Intergovernmental Panel on Climate Change. Climate Change 2013:The Physical Science Basis. Working Group I Contribution to the IPCC Fifth Assessment Report (AR5). Geneva (CHE): IPCC; 2013.

2. Altizer S, Ostfeld RS, Johnson PTJ, Kutz S, Harvell CD. Climate change and infectious diseases: From evidence to a predictive framework. Science. 2013;341(6145): 514-9.

3. Kolstad EW, Johansson KA. Uncertainties associated with quantifying climate change impacts on human health: A case study for diarrhea. Environ Health Perspect. 2011;119(3):299.

4. MajowiczSE, Musto J,Scallan E, AnguloFJ, KirkM, O'Brien SJ, et al. The global burden of nontyphoidal Salmonella gastroenteritis. Clin Infect Dis. 2010;50(6):882-9.

5. Lal A, Baker MG, French NP, Dufour M, Hales S. The epidemiology of human salmonellosis in New Zealand, 1997-2008. Epidemiol Infect. 2011:1-10.

6. Britton E, Hales S, Venugopal K, Baker MG. Positive association between ambient temperature and salmonellosis notifications in New Zealand, 1965-2006. Aust NZ Public Health. 2010;34(2):126-9.

7. Lal A, Ikeda T, French N, Baker MG, Hales S. Climate Variability, Weather and Enteric Disease Incidence in New Zealand: Time Series Analysis. PLoS One. 2013;8(12):e83484.

8. Zhang Y, Bi P,Hiller JE. Climate variations and Salmonella infection in Australian subtropical and tropical regions. Sci Total Environ. 2010;408(3):524-30.
9. D'Souza RM, Becker NG, Hall G, Moodie KBA. Does ambient temperature affect foodborne disease? Epidemiology. 2004;15(1):86-92.

10. Kovats RS, Edwards SJ, Hajat S, Armstrong BG, Ebi KL, Menne B. The effect of temperature on food poisoning: A time-series analysis of salmonellosis in ten European countries. Epidemiol Infect. 2004;132(3):443-53.

11. Fleury M, Charron DF, Holt JD, Allen OB, Maarouf AR. A time series analysis of the relationship of ambient temperature and common bacterial enteric infections in two Canadian provinces. Int JBiometeorol. 2006;50(6):385-91.

12. Bentham G, Langford IH. Environmental temperatures and the incidence of food poisoning in England and Wales. Int J Biometeorol. 2001;45(1):22-6.

13. Sant'Ana AS, Barbosa MS, Destro MT, Landgraf M, Franco BDGM. Growth potential of Salmonella spp. and Listeria monocytogenes in nine types of ready-to-eat vegetables stored at variable temperature conditions during shelf-life. Int J Food Microbiol. 2012;157(1):52-8.

14. Gasparrini A, Armstrong B. Time series analysis on the health effects of temperature: Advancements and limitations. Environ Res. 2010;110(6):633-8.

15. Gasparrini A, Armstrong B. Distributed lag nonlinear models in R: the package dlnm. J Stat Softw. 2011;43(8):1-20.

16. Goldberg MS, Gasparrini A, Armstrong B, Valois MF. The short-term influence of temperature on daily mortality in the temperate climate of Montreal, Canada. Environ Res. 2011;111(6):853-60.

17. Guo $Y$, Barnett AG, Zhang $Y$, Tong $S$, Yu W, Pan $X$. The short-term effect of air pollution on cardiovascular mortality in Tianjin, China: Comparison of time series and case-crossover analyses. Sci Total Environ. 2010;409(2):300-6

18. The Institute of Environmental Science and Research. Public Health Surveillance. Wellington (NZ): Government of New Zealand; 2012.

19. Ministry of Health. Communicable Disease Control Manual.Wellington (NZ): Government of New Zealand; 2012.

20. Gasparrini A, Armstrong B, Kenward MG. Distributed lag non-linear models. Stat Med. 2010;29(21):2224-34.

21. Armstrong B. Models for the relationship between ambient temperature and daily mortality. Epidemiology. 2006;17(6):624-31.

22. Gasparrini A, Armstrong B. Reducing and metaanalysing estimates from distributed lag nonlinear models. BMC Med Res Methodol. 2013;13:1. doi:10.1186/1471-2288-13-1.

23. Lin H, Zou H, Wang Q, Liu C, Lang L, Hou X, et al. Shortterm effect of El Nino-southern oscillation on pediatric hand, foot and mouth disease in Shenzhen, China. PloS One. 2013;8(7):e65585.

24. Zhang Y, Li S, Pan X, Tong S, Jaakkola JJ, Gasparrini $A$, et al. The effects of ambient temperature on cerebrovascular mortality: An epidemiologic study in four climatic zones in China. Environ Health. 2014;13(1):24.

25. R Development Core Team. R: A Language and Environment for Statistical Computing. Vienna (AUST): R Foundation for Statistical Computing; 2012.

26. Zhang $Y, B i P$, Hiller J. Climate variations and salmonellosis transmission in Adelaide, South Australia: A comparison between regression models. Int J Biometeorol. 2008;52(3):179-87.

27. Grjibovski A, Bushueva V, Boltenkov V, Buzinov R, Degteva G, Yurasova E, et al. Climate variations and salmonellosis in northwest Russia: A time-series analysis. Epidemiol Infect. 2013;141(02):269-76.

28. Grjibovski A, Kosbayeva A, Menne B. The effect of ambient air temperature and precipitation on monthly counts of salmonellosis in four regions of Kazakhstan, Central Asia, in 2000-2010. Epidemiol Infect. 2014;142(3):608-15.

29. Keegan VA, Majowicz SE, Pearl DL, Marshall BJ, Sittler $\mathrm{N}$, Knowles $\mathrm{L}$, et al. Epidemiology of enteric disease in C-EnterNet's pilot site -Waterloo region, Ontario, 1990 to 2004. Can JInfect Dis Med Microbiol. 2009;20(3):79-87.
30. Ravel A, Smolina E, Sargeant JM, Cook A, Marshall B, Fleury MD, et al. Seasonality in human salmonellosis: Assessment of human activities and chicken contamination as driving factors. Foodborne Pathog Dis. 2010;7(7):785-94.

31. Semenza JC, Menne B. Climate change and infectious diseases in Europe. Lancet Infect Dis. 2009;9(6):365-75.

32. Ekdahl K, de Jong B, Wollin R, Andersson Y. Travelassociated non-typhoidal salmonellosis: Geographical and seasonal differences and serotype distribution. Clin Microbiol Infect. 2005;11(2):138-44.

33. Eberhart-Phillips J, Walker N, Garrett N, Bell D, Sinclair $D$, RaingerW, et al.Campylobacteriosis in New Zealand: Results of a case-control study.J Jepidemiol Community Health. 1997;51(6):686-91.

34. Trenberth K. Atmospheric Moisture Residence Times and Cycling: Implications for Rainfall Rates and Climate Change. Climatic Change. 1998;39(4):667-94.

35. Easterling DR, Evans JL, Groisman PY, KarlTR, Kunkel KE Ambenje P.Observed variability and trends in extreme climate events: A brief review. Bull Am Meteorol Soc 2000;81(3):417-25.

36. Palmer TN, Raisanen J. Quantifying the risk of extreme seasonal precipitation events in a changing climate. Nature. 2002;415(6871):512-4.

37. Alley M, Connolly J, Fenwick S, Mackereth G, Leyland $M$, Rogers $L$, et al. An epidemic of salmonellosis caused by Salmonella Typhimurium DT160 in wild birds and humans in New Zealand. NZ Vet J. 2002;50(5):170-6.

38. Clark RG, FenwickSG, Nicol CM, Marchant RM, Swanney $\mathrm{S}$, Gill JM, et al. Salmonella Brandenburg-emergence of a new strain affecting stock and humans in the South Island of New Zealand. N Z Vet J. 2004;52(1):26-36.

39. Curriero FC, Patz JA, Rose JB, Lele S. The association between extreme precipitation and waterborne disease outbreaks in the United States, 1948-1994. Am J Public Health. 2001;91(8):1194-9.

40. Drayna P, McLellan SL, Simpson P, Li SH, Gorelick MH. Association between rainfall and pediatric emergency department visits for acute gastrointestinal illness. Environ Health Perspect. 2010;118(10):1439.

41. Signor R, Roser D, Ashbolt N, Ball J. Quantifying the impact of runoff events on microbiological contaminant concentrations entering surface drinking source waters. J Water Health. 2005;3:453-68.

42. Lake R, Adlam S, Perera S, Campbell D, Baker M. SHORT REPORT The disease pyramid for acute gastrointestinal illness in New Zealand. Epidemiol Infect. 2010;138(10):1468-71.

43. Sears A, Baker MG, Wilson N, Marshall J, Muellner $P_{\text {, }}$ Campbell DM, et al. Marked campylobacteriosis decline after interventions aimed at poultry, New Zealand. Emerg Infect Dis. 2011;17(6):1007-15.

44. McCarthy ND, Gillespie IA, Lawson AJ, Richardson J, Neal KR, Hawtin PR, et al. Molecular epidemiology of human Campylobacter jejuni shows association between seasonal and international patterns of disease. Epidemiol Infect. 2012;140(12):2247-55.

45. O'Brien SJ, de Valk H. Salmonella - "old" organism, continued challenges. Euro Surveill. 2003;8(2):29-31.

46. Brooks JT, Matyas BT, Fontana J, DeGroot MA, Beuchat LR, Hoekstra M, et al. An outbreak of Salmonella serotype Typhimurium infections with an unusually long incubation period. Foodborne Pathog Dis. 2012;9(3):245-8.

\section{Supporting Information}

Additional supporting information may be found in the online version of this article:

Supplementary Figure 1: Histogram of model residuals for the selected models showing the association between average maximum weekly temperature and salmonellosis risk. 